\title{
Allele loss, replication errors and loss of expression of E-cadherin in colorectal cancers
}

\author{
M Ilyas`, I P M Tomlinson`, A Hanby, I C Talbot, W F Bodmer
}

${ }^{\star}$ Both authors

contributed equally to this work.

\section{Cancer}

Immunogenetics

Laboratory,

Imperial Cancer

Research Fund,

Institute of Molecular

Medicine,

John Radcliffe

Hospital,

Headington,

Oxford OX3 9DU

$M$ Ilyas

W F Bodmer

Cancer Genetics

Laboratory,

Imperial Cancer

Research Fund,

44 Lincoln's Inn Fields,

London WC2A 3PX

$M$ Ilyas

I P M Tomlinson

W F Bodmer

Molecular

Carcinogenesis

Laboratories,

Institute of Cancer

Research,

The Royal Marsden

Hospital, Sutton,

Surrey SH2 5NG

I P M Tomlinson

Colorectal Cancer Unit and Academic

Department of

Pathology,

St Mark's Hospital,

Watford Road,

Harrow HA1 3UJ

I C Talbot

Correspondence to

Dr M Ilyas,

Colorectal Cancer Unit

Imperial Cancer Research

Fund, St Mark's Hospital,

Watford Road,

Harrow HA1 3UJ.

Accepted for publication

31 October 1996

\begin{abstract}
Background-Loss of E-cadherin expression has been implicated in the development of invasive characteristics in colorectal carcinomas. Failure to express E-cadherin may result from mutations of the E-cadherin gene (HSECAD).
\end{abstract}

Aims-To examine the correlation between E-cadherin expression and genetic changes at HSECAD; and to examine differences in E-cadherin expression and genetic changes at HSECAD between three different groups of colorectal cancer - replication error positive (RER+) sporadic cancers, RER- sporadic cancers and ulcerative colitis associated cancers. Subjects and methods-Sixty eight colorectal cancers ( 22 RER+ sporadic cancers, 32 RER- sporadic cancers and 14 ulcerative colitis associated cancers) were studied using immunohistochemistry and for allele loss at the HSECAD locus. Exon 16 of $H S E C A D$ contains several mononucleotide repeat tracts which are very similar to microsatellite repeats and which may be susceptible to replication errors (manifest as new alleles). All cases were also examined for new alleles in exon 16.

Results-Absent or decreased E-cadherin protein expression was found in $27(38 \%)$ of 68 colorectal cancers and the pattern of expression did not differ significantly among the three tumour groups. Allele loss occurred at $H S E C A D$ in four $(10 \%)$ of 40 informative cancers and there were no differences between the three subgroups. New alleles at exon 16 were detected in three $(14 \%)$ of 22 RER+ tumours; no new alleles were detected in RER- or ulcerative colitis associated cancers. Overall, there was no correlation between allelic loss or exon 16 replication errors and immunohistochemical E-cadherin expression.

Conclusions-(1) Loss of E-cadherin expression probably does not occur as a result of mutation at the HSECAD locus in colorectal cancers. (2) There is no difference in the frequency of loss of heterozygosity at HSECAD among RER+, RER- and ulcerative colitis associated colorectal cancers. (Gut 1997; 40: 654-659)

Keywords: colorectal cancer, replication errors, E-cadherin expression, E-cadherin mutation, loss of heterozygosity.

The multistep nature of carcinogenesis is well accepted. ${ }^{12}$ There is, however, evidence of differences among the genetic pathways involved in the pathogenesis of distinct types of colorectal cancer. Most sporadic colorectal cancers probably develop in accordance with the model proposed by Fearon and Vogelstein, ${ }^{3}$ but about $10-20 \%$ of sporadic colorectal cancers, and nearly all colorectal cancers in the hereditary non-polyposis colorectal cancer (HNPCC) syndrome, have DNA mismatch repair defects, leading to replication errors (RERs). ${ }^{45}$ Tumours which have the RER phenotype (RER+) may progress through mutations of genes not usually mutated in sporadic colorectal carcinoma. Genes such as the type II transforming growth factor (TGF) $\beta$ receptor are rich in mononucleotide repeat sequences and therefore may be prone to mutation in RER+ tumours. ${ }^{6}$ Another type of colorectal cancer arising in ulcerative colitis (ulcerative colitis associated colorectal cancer) displays different clinicopathological features from sporadic colorectal cancers. Evidence, such as a low frequency of APC and K-ras mutations ${ }^{7-9}$ and low frequency of $\mathrm{Bcl}-2$ over-expression, suggests that these tumours may also develop along a genetic pathway distinct from that of sporadic RER- colorectal cancers. One of the features of malignancy is invasion into the stroma and surrounding tissues, leading eventually to tumour dissemination. This process may be different from tumour growth and may involve mutations at different genetic loci. One of the genes implicated in the progression to tumour invasion is E-cadherin, which codes for one of a large family of calcium-dependent cell adhesion molecules. ${ }^{10}$ The E-cadherin protein is a transmembrane molecule which is complexed in the cytoplasm with $\alpha-, \beta$ - and $\gamma$-catenin ${ }^{11} 12$ to form a functional unit which we term the E-cadherin-catenin unit (ECCU). Functional regulation of the ECCU may occur, in part, through the APC protein (which competes with $\mathrm{E}$-cadherin for binding sites on $\beta$-catenin $)^{13-15}$ and disruption of any of the components of the ECCU results in loss of E-cadherin-mediated adhesion. ${ }^{16}{ }^{17}$ E-cadherin has a morphoregulatory role during embryogenesis, probably through its control of cell motility, ${ }^{18}$ and loss of expression of E-cadherin has been observed in many malignant epithelial tumours. ${ }^{19-22}$ Many studies have shown loss of E-cadherin expression in colorectal cancers and this, in general, has mirrored loss of differentiation. ${ }^{23-25}$ Other studies, however, have cast some doubt on the importance of E-cadherin expression as a factor in the progression of colorectal cancers - for example, some colorectal cancers have high E-cadherin expression in the intravascular component or in lymph node metastases, but low E-cadherin expression overall. $^{26-28}$ 
E-cadherin may act as an "invasionsuppressor" gene. It is not clear, however, whether loss of E-cadherin expression in colorectal cancers occurs (i) as a result of mutations at the E-cadherin (HSECAD) locus, (ii) secondary to mutations at other loci which regulate E-cadherin, or (iii) as an epiphenomenon consequent to tumour progression. Although HSECAD mutations have been reported in many epithelial cancers, ${ }^{29-32}$ few mutations have been reported in colorectal cancers. HSECAD consists of 16 exons and maps to chromosome $16 \mathrm{q} 22 . .^{33}$ Exon 16 is the largest exon (2269 base pairs) and codes almost entirely for an unusually long 3' UTR (untranslated region) in the HSECAD mRNA. This region contains unusual poly(T) and poly(A) tracts which may be susceptible to replication errors in tumours. Although mutations within the 3' UTR are unlikely to affect the sequence of the E-cadherin protein, they may influence mRNA secondary structure and stability, and hence E-cadherin protein concentrations.

In this study we examined immunohistochemical expression of E-cadherin protein in three different types of colorectal cancer (RERsporadic colorectal cancers, RER+ sporadic colorectal cancers and ulcerative colitis associated colorectal cancers). As a means of analysing E-cadherin mutations, we studied allele loss at a polymorphic marker near to HSECAD in these colorectal cancers. In addition, each cancer was analysed for RERs in the poly(T) and poly(A) mononucleotide repeats in HSECAD exon 16. The immunohistochemical and genetic data were then correlated in order to suggest whether or not mutations at HSECAD could explain the patterns of E-cadherin expression that were observed.

\section{Methods}

\section{CASE SELECTION}

We selected 68 cases of colorectal cancer from the archives of the Colorectal Cancer Unit and the Academic Department of Pathology at St Mark's Hospital for DNA analysis. Forty nine of these cases were sporadic colorectal cancers and had previously been categorised into 31 RER- and 18 RER+ cancers. ${ }^{34}$ To this group, we added a further four colorectal cancers that had been typed as RER+, one colorectal cancer typed as RER- and 14 as associated with ulcerative colitis. The RER status of the ulcerative colitis associated colorectal cancers was determined, but they were analysed without regard to their RER status in this study, in order to prevent subdivision of these cancers into small groups.

\section{IMMUNOHISTOCHEMISTRY}

Freshly cut $4 \mu \mathrm{m}$ sections of formalin fixed, paraffin wax embedded tissue were analysed using immunohistochemistry. Sections were dewaxed in xylene and re-hydrated through graded alcohols. Endogenous peroxidase activity was blocked by incubation for 15 minutes in $0.5 \%$ hydrogen peroxide in methanol. Anti- gen retrieval was by heating these sections in a pressure cooker at 15 psi for 30 minutes in $0 \cdot 1$ $M$ sodium citrate solution ( $\mathrm{pH} 6 \cdot 0)$. Sections were incubated for 30 minutes with normal rabbit serum (Dako, High Wycombe, UK) and after blotting off the normal serum, they were incubated overnight at room temperature with a mouse monoclonal antibody directed against E-cadherin (HECD-1; ICRF). Bound antibody was then detected using the labelled streptavidin method. The sections were incubated for one hour each with a 1 in 200 dilution of biotinylated rabbit anti-mouse (Dako) and horseradish peroxidase labelled streptavidin (Dako), respectively. Diaminobenzidine was used as the chromogen and negative controls (in which phosphate buffered saline replaced the primary antibody) were included in every experiment. The immunohistochemistry was reviewed independently by two pathologists (MI, $\mathrm{AH}$ ) who were unaware of the categorisation of the tumours. Only membrane staining was regarded as positive staining and the tumours were scored semiquantitatively in accordance with the proportion of positive tumour cells, as follows: $0=0 \% ; \quad+=1-25 \%$ positive tumour cells; $++=26-50 \% ;+++>50 \%$.

\section{ALLELE LOSS}

Paired samples of genomic DNA from normal tissue and from the corresponding colorectal cancer were extracted using standard methods or the Nucleon extraction kit (Scotlab, UK). PCR mixtures containing 50-250 ng template DNA were used in a final volume of $50 \mu l$ with reaction concentrations of $1 \times$ standard PCR buffer (Promega), $1.5 \mathrm{mM} \mathrm{Mg}^{2+}, 0.5 \mu \mathrm{M}$ dNTPs, $0.4 \mu \mathrm{M}$ each specific oligonucleotide primer, and 1 unit Taq polymerase. Primers were selected for the locus D16S520 and the sequences were obtained from the Genome Database (GDB ID G00-200-145). The primer sequences were 5'-GCT TAG TCA TAC GAG CGG-3' (primer name AFMal35xg5a) and 5'-TCC ACA GCC ATG TAA ACC-3' (primer name AFMal35xg5m). The PCR amplification protocol was $94^{\circ} \mathrm{C}$ for three minutes for one cycle, $94^{\circ} \mathrm{C}$ for one minute, $55^{\circ} \mathrm{C}$ for one minute and $72^{\circ} \mathrm{C}$ for five minutes for 35 cycles followed by an extension step at $72^{\circ} \mathrm{C}$ for five minutes. PCR products were heated to $90^{\circ} \mathrm{C}$ for five minutes and electrophoresed on a $6 \%$ acrylamide sequencing gel (Sequagel) under denaturing conditions for two to four hours. DNA was blotted overnight onto Hybond $\mathrm{N}+$ membranes (Amersham, Little Chalfont, UK). PCR products were detected using the enhanced chemiluminescence technique (ECL) (Amersham, UK), using a randomly elongated oligonucleotide primer as a specific probe for each locus. Products were visualised by exposing membranes to Hyperfilm (Amersham, UK) overnight. Cases were regarded as showing allele loss at D16S520 if there was heterozygosity in the normal tissue and an unequivocal reduction in the intensity of one of the bands (agreed by at least two observers (MI, IPMT) independently). Extra bands in tumour samples that differed by 
multiples of 2 base pairs from their normal counterparts were scored as replication errors, but data from D16S520 were not used in classifying tumours as RER+ and RER-.

EXON 16

All cases were investigated for mutations in exon 16 region which contains the three mononucleotide repeats, $T_{15}, T_{12}$ and $A_{9}$. PCR primers flanking these sequences were designed using the OLIGO program to produce

TABLE I Immunohistochemical expression of E-cadherin in colorectal cancer

\begin{tabular}{llclc}
\hline $\begin{array}{l}\text { Intensity of } \\
\text { expression }\end{array}$ & $\begin{array}{l}\text { Sporadic } R E R- \\
(n=32)\end{array}$ & $\begin{array}{l}\text { Sporadic } R E R+ \\
(n=22)\end{array}$ & $\begin{array}{l}\text { UC associated } \\
(n=14)\end{array}$ & $\begin{array}{l}\text { Overall } \\
(n=68)\end{array}$ \\
\hline 0 & 0 & 3 & 1 & 4 \\
+ & 10 & 7 & 5 & 22 \\
++ & 12 & 9 & 3 & 24 \\
+++ & 10 & 3 & 5 & 26 \\
Negative $(0 /+)$ & 10 & 10 & 6 & 42 \\
Positive $(+++++)$ & 22 & 12 & 8 & \\
\hline
\end{tabular}

Association $\chi_{2}^{2}$ (negative $(0 /+) v$ positive $\left.(++/+++)\right)=2 \cdot 59, \mathrm{p}>0 \cdot 1$. $\mathrm{UC}=$ ulcerative colitis.
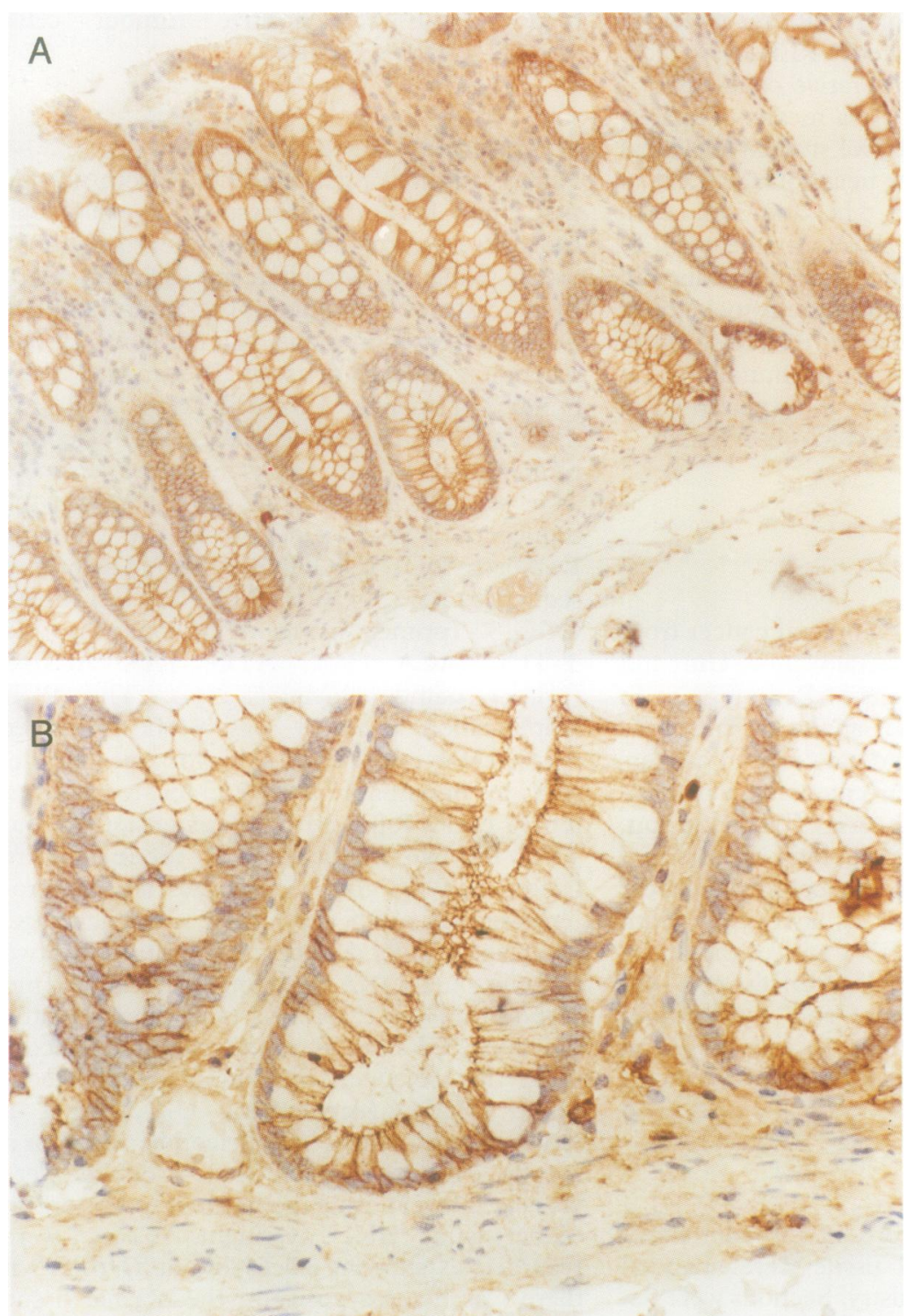

Figure 1: Immunohistochemical E-cadherin expression in non-neoplastic mucosa. Figure $1 A$ shows that there is positive staining in all the cells along the whole crypt axis. Figure $1 B$ is a higher power picture showing that expression occurs on the intercellular membranes and has a punctate quality. a 298 base pair product. The sequences of the primers were 5'-CCG ATA GAA TGA GAC CCT GTC-3' and 5'-AAG TTT GTG TTA GAA AAG TTT-3'. In each case the reaction volume was $50 \mu \mathrm{l}$ as described earlier. The cycling conditions were $94^{\circ} \mathrm{C}$ for five minutes for one cycle, $94^{\circ} \mathrm{C}$ for one minute, $50^{\circ} \mathrm{C}$ for one minute and $72^{\circ} \mathrm{C}$ for one minute for 35 cycles, followed by an extension step at $72^{\circ} \mathrm{C}$ for five minutes. The PCR product was detected using the ECL method as described earlier. Those cases that showed a change in the size of the product (bandshift), suggestive of a new allele with a change in mononucleotide repeat number, were sequenced. Data from exon 16 of HSECAD were not used in classifying tumours as RER+ and RER-.

DNA SEQUENCING

In all tumours with bandshifts in exon 16 of HSECAD on gel electrophoresis, PCR products from tumour DNAs and their normal controls were sequenced to confirm that these changes arose from slippage within one of the poly(A) or poly(T) tracts. Oligonucleotides and unincorporated dNTPs were removed using a Sephadex G50 spun column (Pharmacia). Purified PCR product $(5 \mu \mathrm{l})$ was used in a thermocycle sequencing reaction with the Ready Reaction Dye Terminator Cycle Sequencing kit (ABI, Foster City, California, USA). Polyacrylamide gel electrophoresis was performed using standard conditions on a 373 Prism fluorescence-based, semi-automated DNA sequencer (ABI). All sequencing reactions were performed in duplicate and in comparison with normal control samples.

\section{Results}

Immunohistochemical and genetic data were analysed using a simple $\chi^{2}$ test to study differences between the three tumour groups and any association between genetic changes and immunohistochemical changes.

\section{IMMUNOHISTOCHEMISTRY}

Table I shows the results of the immunostaining for E-cadherin in the different types of colorectal cancer. Table II shows a comparison between tumour grade and E-cadherin staining. Normal epithelium showed punctate basolateral membrane staining along the whole length of the crypt (Fig 1) and this was used

TABLE II Correlation of E-cadherin expression with tumour differentiation

\begin{tabular}{lllll}
\hline & \multicolumn{3}{l}{ Tumour differentiation } & \\
\cline { 2 - 4 } Intensity of expression & $\begin{array}{l}\text { Well } \\
(n=7)\end{array}$ & $\begin{array}{l}\text { Moderate } \\
(n=45)\end{array}$ & $\begin{array}{l}\text { Poor } \\
(n=16)\end{array}$ & $\begin{array}{l}\text { Overall } \\
(n=68)\end{array}$ \\
\hline 0 & 0 & 3 & 1 & 4 \\
+ & 3 & 13 & 6 & 22 \\
++ & 0 & 18 & 6 & 24 \\
+++ & 4 & 11 & 3 & 18 \\
Negative $(0 /+)$ & 3 & 16 & 7 & 26 \\
Positive $(++/+++)$ & 4 & 29 & 9 & 42 \\
\hline
\end{tabular}

Association $\chi^{2}{ }_{1}$ (well and moderately differentiated $v$ poorly differentiated colorectal cancers $)=0 \cdot 3, p>0 \cdot 8$. 

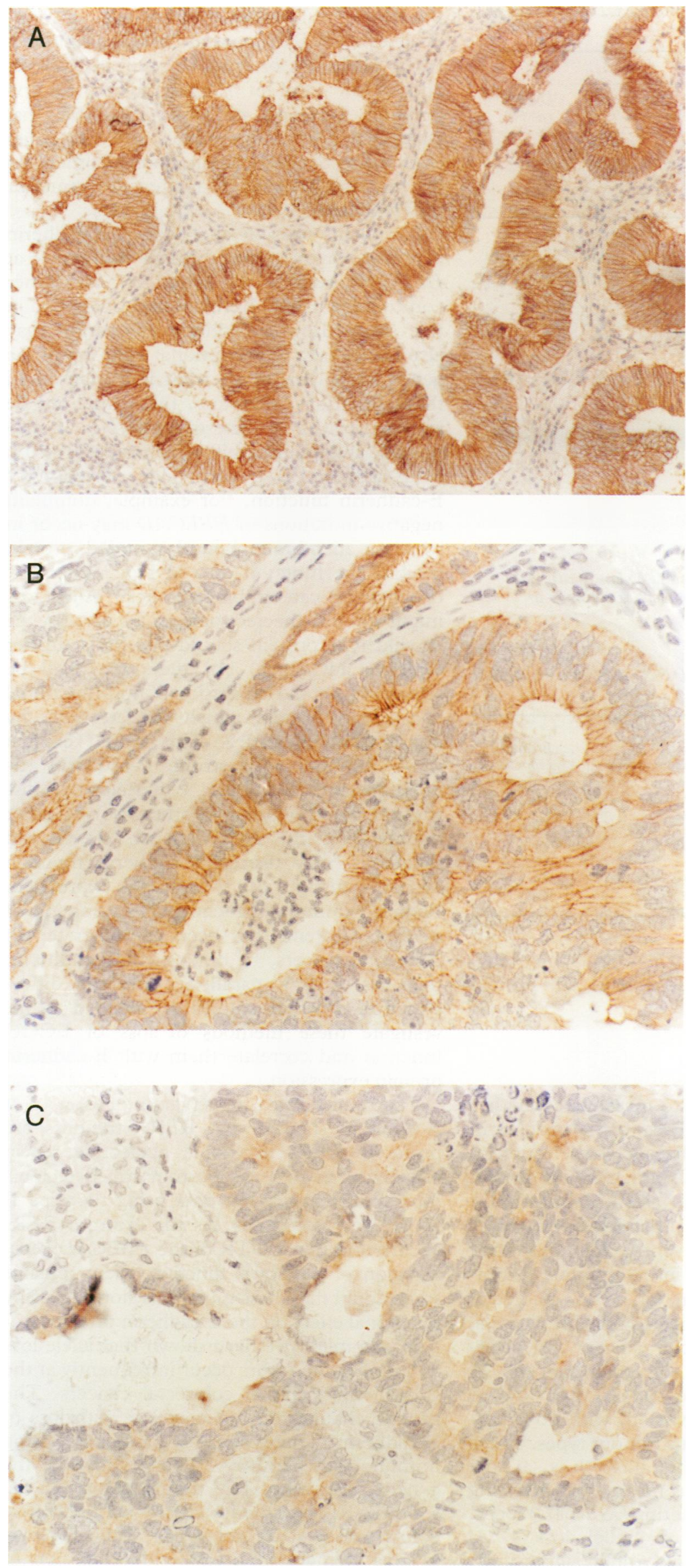

Figure 2: Immunohistochemical E-cadherin expression in colorectal cancers. (A) Strong membranous staining in most cells in a well differentiated tumour. (B) Heterogeneous membranous staining in a moderately differentiated tumour. (C) A poorly differentiated tumour in which there is almost no membranous $E$-cadherin expression. Mild cytoplasmic expression is evident, but this tumour would be regarded as negative for expression as membrane localisation is essential for $E$-cadherin function. as an internal positive control. Most tumours showed heterogeneous staining with variable degrees of both membrane and cytoplasmic staining (Fig 2). In some areas, there was intense cytoplasmic staining with no membrane staining and a few cases were negative for both cytoplasmic and membrane staining. Those cases which showed membrane staining in over $25 \%$ of tumour cells were regarded as positive for E-cadherin expression. Cytoplasmic staining, in the absence of membrane staining, was regarded as negative, as membrane localisation is essential for E-cadherin function. Ten (31\%) of 32 RER-tumours, 10 $(45 \%)$ of 22 RER+ tumours and six $(43 \%)$ of 14 ulcerative colitis associated colorectal cancers were negative for E-cadherin expression. There was a trend for reduced expression in the RER+ tumours compared with either RER- tumours or ulcerative colitis associated colorectal cancers, but this was not statistically significant (Table I). The pattern of expression of E-cadherin was broadly similar in all tumour grades (Table II).

\section{ALLELE LOSS}

The results of the PCR for allele loss at D16S520 are shown in Table III and examples of allele loss are shown in Fig 3. Of the 68 cases of colorectal cancer, 40 (59\%) were informative (heterozygous). Two (9\%) of 21 RERtumours, two $(16 \%)$ of 13 RER+ tumours and none of the ulcerative colitis associated colorectal cancers showed allele loss. There was no significant difference among the frequencies of allele loss in each type of colorectal cancer (Table II). None of the RER-cancers showed microsatellite instability at D16S520, but four $(18 \%)$ of 22 RER+ and one (7\%) of 14 ulcerative colitis associated colorectal cancers were unstable at this locus.

EXON 16 REPLICATION ERRORS

After analysis of the mononucleotide repeat region of exon 16, new alleles were found in three $(14 \%)$ of 22 RER+ tumours, but in none of the RER- or ulcerative colitis associated colorectal cancers. Examples of bandshifts, indicating replication errors (and subsequently confirmed by sequencing), are shown in Fig 4. All replication errors occurred within the mononucleotide repeat sequences and consisted of single base pair deletions.

CORRELATION OF GENETIC DATA (ALLELE LOSS AND EXON 16 REPLICATION ERRORS) WITH E-CADHERIN EXPRESSION

Table IV shows the immunohistochemical expression of E-cadherin in all cases with allele loss at D16S520 or replication errors in exon 16 of the HSECAD gene. Only two $(29 \%)$ of seven cancers with allele loss or exon 16 replication errors had low levels ( 0 or + ) of E-cadherin expression, compared with $38 \%$ of all cancers studied. Although the number of tumours is small, there is clearly no association between allele loss or exon 16 replication errors 
TABLE III Frequencies of allele loss and microsatellite instability at the D16S520 locus in colorectal cancers

\begin{tabular}{lllll}
\hline & \multicolumn{2}{l}{ Tumour type } & & \\
\cline { 2 - 4 } & $\begin{array}{l}\text { Sporadic RER } \\
(n=32)\end{array}$ & $\begin{array}{l}\text { Sporadic RER+ } \\
(n=22)\end{array}$ & $\begin{array}{l}\text { UC associated } \\
(n=14)\end{array}$ & $\begin{array}{l}\text { Overall } \\
(n=68)\end{array}$ \\
\hline Allele loss & 2 & 2 & 0 & 4 \\
No allele loss & 19 & 7 & 5 & 31 \\
RER & 0 & 4 & 1 & 5 \\
Non-informative & 11 & 9 & 8 & 28 \\
\hline
\end{tabular}

Association $\chi_{2}^{2}$ (allele loss $v$ no allele loss) $\sim 0, \mathrm{p}>0 \cdot 9$

$\mathrm{UC}=$ ulcerative colitis.
A

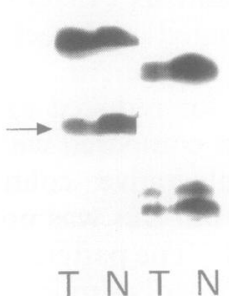

B

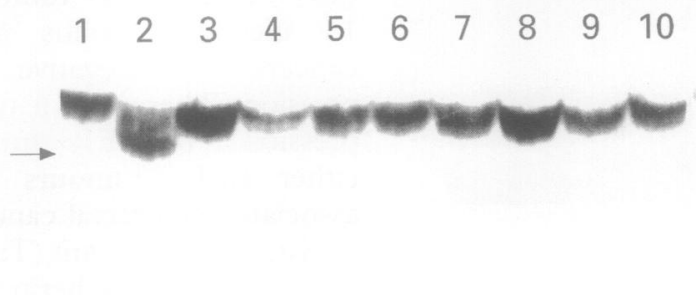

Figure 3: (A) Allele loss (arrow) in case 29 (left) at D16S520 and no loss in case 205 (right). (B) RER in HSECAD exon 16 in case 59 (second from left) resulting in a bandshift.

TABLE IV E-cadherin expression in cancers with allele loss at D16S520 or exon $16 R E R s$ at HSECAD

\begin{tabular}{lllll}
\hline & $\begin{array}{l}\text { Tumour type: } \\
\text { RER+/RER-/ } \\
\text { UC associated }\end{array}$ & $\begin{array}{l}\text { Allele loss/replication } \\
\text { error at D16S520 }\end{array}$ & $\begin{array}{l}\text { Exon 16 } \\
\text { replication error }\end{array}$ & $\begin{array}{l}\text { E-cadherin } \\
\text { expression }\end{array}$ \\
\hline 29 & RER+ & Loss & No & ++ \\
45 & RER+ & Replication errors & Yes & ++ \\
51 & RER- & Loss & No & ++ \\
59 & RER+ & No loss & Yes & ++ \\
105 & RER- & Loss & No & +++ \\
109 & RER+ & Loss & No & + \\
113 & RER + & Not informative & Yes & 0 \\
\hline
\end{tabular}

$\mathrm{UC}=$ ulcerative colitis.

at HSECAD and a low level of protein expression in this series.

\section{Discussion}

In this study we aimed to investigate whether loss of expression of E-cadherin protein in colorectal cancers was because of selection of a mutation in $H S E C A D$, which would give an advantage for tumour invasion, or whether it occurred secondary to other mutations or as an epiphenomenal event. We examined E-cadherin expression in 68 tumours, comprising three different types of colorectal cancer (RER- sporadic colorectal cancers, RER+ sporadic colorectal cancers and ulcerative colitis associated colorectal cancers). A mean of $38 \%$ of these cancers had low or lacked E-cadherin expression, with no differences between the various tumour types. These cases were studied for allele loss at the D16S520 marker as a means of analysing mutations at the E-cadherin (HSECAD) locus. A relatively low frequency of allele loss $(10 \%)$ was found which did not differ significantly among the three colorectal cancer groups. We also searched for replication errors in mononucleotide repeat sequences in exon 16 of $H S E C A D$ and found replication errors at this site in $14 \%$ of RER+ cancers, but in none of the RER- or ulcerative colitis associated colorectal cancers. No association was found between allele loss or exon 16 replication errors and a low level of E-cadherin protein expression. It seems probable, therefore, that changes in E-cadherin expression occur either as the direct result of mutations at other loci or as epiphenomena related to tumour differentiation.

It remains possible that loss of E-cadherin expression may occur through mutations at $H S E C A D$, such as the promoter ${ }^{35}$ and other control regions that have not been identified in this study. Low E-cadherin expression may also result from transcriptional silencing of the gene $^{36}$ secondary to aberrant methylation. In these situations, therefore, there may not be associated loss of heterozygosity. It is also possible that immunohistochemical expression of E-cadherin is a very poor reflection of E-cadherin function. For example, dominant negative mutations of $H S E C A D$ may occur in which a membrane bound mutated protein inhibits the function of wild type protein by occupying $\beta$-catenin binding sites. ${ }^{37}$ Allele loss might still be expected to occur (as the absence of wild type protein should provide a further selective advantage) but there may still be strong membrane expression of non-functional E-cadherin protein which is detectable by immunohistochemistry. This would explain those tumours with strong E-cadherin expression and allele loss. Alternatively, disruption (by mutation or otherwise) of other members of the ECCU, such as $\alpha$ - and $\beta$-catenin, may disrupt E-cadherin function without change of E-cadherin expression. Reduced immunohistochemical expression of $\alpha$ - and $\beta$-catenin has been demonstrated in colorectal cancers, ${ }^{38}{ }^{39}$ but, as with E-cadherin, this has usually parallelled tumour differentiation. Further studies are needed to investigate these methods of loss of ECCU function and correlate them with E-cadherin protein expression.

The results of the investigation of exon 16 of E-cadherin showed that RER+ tumours are prone to RERs in exonic nucleotide repeat sequences, as well as non-transcribed regions, thus confirming recent data using the type II TGF $\beta$ receptor genes. As the exon 16 RERs occurred in the $3^{\prime}$ UTR of the HSECAD gene, a region of unknown function, there remains some doubt that these mutations alone have any functional effect on the E-cadherin protein.

In summary, we have shown that allele loss and replication errors occur infrequently at the E-cadherin locus in colorectal cancers. The genetic changes do not correlate with loss of E-cadherin expression as assessed using immunohistochemistry. Thus, although the genetic pathways for tumour invasion in sporadic RER+, sporadic RER- and ulcerative colitis associated colorectal cancers may involve changes in E-cadherin expression or function, they probably do not involve E-cadherin mutation.

We would like to thank Mrs A Sydow for typing the manuscript and Messrs George Elia and Stephen Childs for cutting the sections for immunohistochemistry. 
1 Foulds L. The natural history of cancer. $\mathcal{F}$ Chronic Dis 1958; 8: 2-37.

2 Weinberg RA. Oncogenes, antioncogenes, and the molecular bases of multistep carcinogenesis. Cancer Res 1989; 49: 3713-21.

3 Fearon ER, Vogelstein B. A genetic model for colorectal tumorigenesis. Cell 1990; 61: 759-67.

4 Peltomaki P. Microsatellite instability and hereditary nonpolyposis colon cancer. $\mathcal{F}$ Pathol 1995; 176: 329-30.

5 Radman M, Wagner R. Carcinogenesis. Missing mismatch repair. Nature 1993; 366: 722.

6 Parsons R, Myeroff L, Liu B, Willson J, Markowitz S, Kinzler K, Vogelstein B. Microsatellite instability and mutations of the transforming growth factor $\beta$ type II receptor gene in colorectal cancer. Cancer Res 1995; 55: 5548-50.

7 Redston M, Papadopoulos N, Caldas C, Kinzler K, Kern S. Common occurrence of APC and K-ras mutation in the spectrum of colitis-associated neoplasias. Gastroenterology 1995; 108: 383-92.

8 Tarmin L, Yin J, Harpaz N, Kozam M, Noordzij J, Antonio LB, et al. Adenomatous polyposis coli gene mutations in ulcerative colitis-associated dysplasias and mutations in ulcerative colitis-associated dysplasias and cancers versus sp

9 Bell SM, Kelly SA, Hoyle JA, Lewis FA, Taylor GR, Thompson $\mathrm{H}$, et al. C-ki-ras gene mutations in dysplasia and carcinomas complicating ulcerative colitis. $\mathrm{Br} \mathcal{F}$ Cancer 1991; 64: 174-8.

10 Takeichi M. Cadherins: a molecular family important in selective cell-cell adhesion. Annu Rev Biochem 1990; 59: 237-52.

11 Hinck L, Nathke IS, Papkoff J, Nelson WJ. Dynamics of cadherin/catenin complex formation: novel protein 1994; 125: 1327-40.

12 Gumbiner BM, McCrea PD. Catenins as mediators of the cytoplasmic functions of cadherins. $\mathcal{F}$ Cell Sci Suppl 1993; 17: 155-8.

13 Hulsken J, Behrens J, Birchmeier W. Tumor-suppressor gene products in cell contacts: the E-cadherin-APC-armadillo connection. Curr Opin Cell Biol 1994; 6: 711-6.

14 Hulsken J, Birchmeier W, Behrens J. E-cadherin and APC compete for the interaction with beta-catenin and the cytoskeleton. $\mathcal{F}$ Cell Biol 1994; 127: 2061-9.

15 Rubinfeld B, Souza B, Albert I, Muller O, Chamberlain SH, Masiarz FR, et al. Association of the APC gene product with beta-catenin. Science 1993; 262: 1731-4.

16 Cowin P. Unraveling the cytoplasmic interactions of the E-cadherin superfamily. Proc Natl Acad Sci USA 1994; 91: 10759-61.

17 Shimoyama $Y$, Nagafuchi A, Fujita $S$, Gotoh $M$, Takeichi $M$, Tsukita $S$, et al. Cadherin dysfunction in a human cancer cell line: possible involvement of loss of alpha-catenin expression in reduced cell-cell adhesiveness. Cancer Res expression in reduced

18 Takeichi $M$. The E-cadherins: cell-cell adhesion molecules controlling animal morphogenesis. Development 1988; 102: $639-55$

19 Schipper JH, Frixen UH, Behrens J, Unger A, Jahnke K, Birchmeier W. E-cadherin expression in squamous cell carcinomas of head and neck: inverse correlation with tumor dedifferentiation and lymph node metastasis. Cancer Res 1991; 51: 6328-37.

20 Umbas R, Schalken JA, Aalders TW, Carter BS, Karthaus HF, Schaafsma HE, et al. Expression of the cellular adhesion molecular E-cadherin is reduced or absent in high-grade prostate cancer. Cancer Res 1992; 52: 5104-9.

21 Pignatelli M, Ansari TW, Gunter P, Liu D, Hirano S, Takeichi $M$, et al. Loss of membranous E-cadherin expression in pancreatic cancer: correlation with lymph node metastasis, high grade, and advanced stage. $\mathcal{F}$ Pathol 1994; 174: 243-8.
22 Oka $\mathrm{H}$, Shiozaki $\mathrm{H}$, Kobayashi $\mathrm{K}$, Inoue $\mathrm{M}$, Tahara $\mathrm{H}$, Kobayashi $\mathrm{T}$, et al. Expression of E-cadherin cell adhesion molecules in human breast cancer tissues and its relationship to metastasis. Cancer Res 1993; 53: 1696-701.

23 Kinsella AR, Lepts GC, Hill CL, Jones M. Reduced E-cadherin expression correlates with increased invasiveness in colorectal carcinoma cell lines. Clin Exp Metastasis 1994; 12: 335-42.

24 Dorudi S, Hanby AM, Poulsom R, Northover J, Hart IR. Level of expression of E-cadherin mRNA in colorectal cancer correlates with clinical outcome. $B r f$ Cancer 1995; 71: $614-6$.

25 Nigam AK, Savage FJ, Boulos PB, Stamp GW, Liu D, Pignatelli $M$. Loss of cell-cell and cell-matrix adhesion molecules in colorectal cancer. $\mathrm{Br} \mathcal{F}$ Cancer 1993; 68: 507-14.

26 Cowley GP, Smith ME. Modulation of E-cadherin expression and morphological phenotype in the intravascular component of adenocarcinomas. Int 7 Cancer 1995; 60: 325-9.

27 van der Wurff AA, Arends JW, van der Linden EP, ten Kate J, Bosman FT. L-CAM expression in lymph node and liver metastases of colorectal carcinomas. $f$ node and liver metastases

28 Kinsella AR, Green B, Lepts GC, Hill CL, Bowie G, Taylor BA. The role of the cell-cell adhesion molecule E-cadherin in large bowel tumour cell invasion and metastasis. Br f Cancer 1993; 67: 904-9.

29 Becker KF, Atkinson MJ, Reich U, Becker I, Nekarda H, Siewert JR, et al. E-cadherin gene mutations provide clues to diffuse type gastric carcinomas. Cancer Res 1994; 54: 3845-52.

30 Kanai Y, Oda T, Tsuda H, Ochiai A, Hirohashi S. Point mutation of the E-cadherin gene in invasive lobular carcinoma of the breast. Fpn $\mathcal{F}$ Cancer Res 1994; 85: $1035-9$.

31 Oda T, Kanai Y, Oyama T, Yoshiura K, Shimoyama Y, Birchmeier W, et al. E-cadherin gene mutations in human Birchmeier , et al. E-cadherin gene mutations in human gastric carcin $1858-62$.

32 Risinger JI, Berchuck A, Kohler MF, Boyd J. Mutations of the E-cadherin gene in human gynecologic cancers. Nat Genet 1994; 7: 98-102.

33 Bussemakers MJ, van Bokhoven A, Mees SG, Kemler R, Schalken JA. Molecular cloning and characterization of the human E-cadherin cDNA. Mol Biol Rep 1993; 17: 123-8.

34 Ilyas M, Tomlinson IPM, Novelli M, Hanby A, Bodmer WF, Talbot IC. Clinico-pathological features and p53 expression in left-sided sporadic colorectal cancers with and without microsatellite instability. F Pathol 1996; 179: $370-5$.

35 Hennig G, Behrens J, Truss M, Frisch S, Reichmann E, Birchmeier W. Progression of carcinoma cells is associated with alterations in chromatin structure and factor binding at the E-cadherin promoter in vivo. Oncogene 1995; 11 : 475-84.

36 Graff JR, Herman JG, Lapidus RG, Chopra H, Xu R, Jarrard DF, et al. E-cadherin expression is silenced by DNA hypermethylation in human breast and prostate carcinomas. Cancer Res 1995; 55: 5195-9.

37 Birchmeier W, Behrens J, Cadherin expression in carcinomas: role in the formation of cell junctions and the prevention of invasiveness. Biochim Biophys Acta 1994; 1198: $11-26$.

38 Shiozaki $\mathrm{H}$, Iihira $\mathrm{K}$, Oka $\mathrm{H}$, Kadowaki $\mathrm{T}$, Matsui $\mathrm{S}$, Gofuku J, et al. Immunohistochemical detection of A-Catenin expression in human cancers. Am 7 Pathol 1994; 144: 667-74.

39 Takayama ÇT, Shiozaki H, Shibamoto S, Oka H, Kimura Y, Tamura $S$, et al. B Catenin expression in human cancers. Am f Pathol 1996; 148: 39-46. 